\title{
Pengelolahan Bank Sampah dalam Meningkatkan Perekonomian Masyarakat di Desa Banangkah Kecamatan Burneh Kabupaten Bangkalan
}

\author{
Waste Bank Management in Improving the Community Economy in Banangkah Village, \\ Burneh District, Bangkalan Regency
}

Zamnurdin Ma'arif Al Ghaffar ${ }^{*}$, Moh Syamsih ${ }^{2}$, Nur Aizizah Widyati², Catur Wasonowati $^{3}$

Citation: Ghaffar, Z.M.A., Syamsih, M., Widyati, N.A. Wasonowati, C. Pengelolahan Bank Sampah dalam Meningkatkan Perekonomian Masyarakat

di Desa Banangkah Kecamatan Burneh Kabupaten Bangkalan. Buletin Pemberdayaan Masyarakat dan Desa 2021, 1(1), 13-19.

https://doi.org/10.21107/bpmd.v1i1. 11976

Received: July, 2021

Accepted: August, 2021

Published: September, 2021

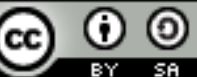

Copyright: (C) 2021 by the authors. Submitted for possible open access publication under the terms and conditions of the Creative Commons Attribution (CC BY SA) license (https://creativecommons.org/license s/by-sa/4.0/).
${ }^{1}$ lmu Kelautan, Universitas Trunojoyo Madura; Jl Raya Telang, Kamal Bangkalan Kode Pos 69162 ; 2,Manajemen, Universitas Trunojoyo Madura; Jl Raya Telang, Kamal Bangkalan Kode Pos 69162; ${ }^{3}$ Agroekoteknologi, Universitas Trunojoyo Madura; Jl Raya Telang, Kamal Bangkalan Kode Pos 69162; *Correspondence: zamnurdin@gmail.com;

\begin{abstract}
Abstrak: Bank sampah merupakan salah satu pengelolahan sampah yang telah dikumpulkan dan di pilah-pilah. Hasil dari pemilahan sampah bertujuan agar sampah dapat dengan mudah di daur ulang sesuai dengan jenisnya, terdapat tiga jenis sampah dalam pengelolahan bank sampah yaitu sampah organik, sampah anorganik dan sampah B3. Sampah yang telah terkumpul selanjutnya akan di jual kepada pengepul. Pengelolahan bank sampah dapat membantu mengurangi pencemaran lingkungan yang disebabkan oleh manusia, selain itu pengelolaan bank sampah dapat membantu pemasukan desa. Salah satu permasalahan yang terjadi di Desa Benangkah yaitu banyaknya sampah plastik yang berserakan di pinggir jalan dan gedung balai desa. Tujuan kegiatan ini yaitu untuk memberikan arahan dan informasi terhadap pengelolahan bank sampah demi meningkatkan kesejahteraan masyarakat sekitar, mengubah pola pikir akan pentingnya menjaga lingkungan dan memiliki sikap peduli terhadap sumber daya alam yang dimiliki sehingga menunjang perekonomian masyarakat sekitar, dari kegiatan ini dapat disimpulkan bahwa pengelolahan bank sampah dapat meningkatkan perekonomian masyarakat di Desa Benangkah Kecamatan Burneh Kabupaten Bangkalan.
\end{abstract}

Keywords: Pengelolahan Bank Sampah, Menjaga Lingkungan, Desa Banangkah

Abstract: Waste bank is one of the waste management that has been collected and sorted. The results of waste sorting aim that waste can be easily recycled according to its type, there are three types of waste in waste bank management namely organic waste, inorganic waste and B3 waste. The collected waste will then be sold to collectors. Waste bank management can help reduce environmental pollution caused by humans, besides that waste bank management can help village income. One of the problems that occur in Benangkah Village is the amount of plastic waste scattered on the roadside and the village hall building. The purpose of this activity is to provide direction and information on the management of waste banks in order to improve the welfare of the surrounding community, change the mindset of the importance of protecting the environment and have a caring attitude towards the natural resources owned so as to support the economy of the surrounding community, from this activity it can be concluded that bank management waste can improve the economy of the community in Benangkah Village, KEC. Burneh KAB. Bangkalan. Keywords: Waste Bank Management, Protecting the Environment, Banangkah Village

\section{PENDAHULUAN}

Indonesia merupakan negara kepulauan terbesar di dunia, dengan potensi sumber daya laut dan pesisir yang melimpah. Wilayah pesisir dan laut memiliki arti penting secara ekonomi bagi kehidupan masyarakat dari dahulu. Sumberdaya hayati laut indonesia dapat dijadikan sebagai penopang hidup masyarakat pesisir atau aset negara. Potensi terumbu karang di laut indonesia sangat besar kurang lebih 14\% terumbu karang di dunia berada di indonesia dengan luas $75.000 \mathrm{~km} 2$, terumbu karang selain menjadi 
rumah bagi biota laut juga bermanfaat sebagai penahan ombak dan pelindung pantai dari abrasi. Potensi perikanan indonesia mencapai 65 juta ton yang terdiri 7,3 juta ton ikan pelagis atau perikanan tangkap dan 57,7 juta ton perikanan budidaya. Sektor budidaya biota laut yang di budidayakan yaitu kepiting, ikan kakap putih, udang dan teripang. Potensi hutan mangrove di indonesia mencapai luas 4,25 juta hektar dan hutan mangrove membantu dalam peningkatan oksigen. Indonesia memiliki tiga ekosistem yaitu ekosistem terumbu karang, ekosistem lamun dan ekosistem mangrove (Baransano dan Jubhar, 2011)

Indonesia merupakan negara yang mempunyai hutan mangrove paling luas di dunia. Berdasarkan data Kementerian Negara Lingkungan Hidup tahun 2006 bahwa luas hutan mangrove Indonesia mencapai 4.3 juta hektar. Sedangkan menurut FAO (2007) bahwa Indonesia mempunyai hutan mangrove seluas 3,062.300 juta hektar pada tahun 2005 yang merupakan $19 \%$ dari total luas hutan mangrove di seluruh dunia. Areal hutan mangrove yang luas antara lain terdapat dipesisir timur sumatera, pesisir kalimantan papua (Irian jaya). Papua mempunyai hutan mangrove terluas yaitu sekitar 2.934.000 ha atau 77.1\% luas mangrove di Indonesia (Ghufran, 2012)

Indonesia merupakan negara yang memiliki sumber daya alam yang melimpah. hasil alam dari laut dan daratan dapat dijadikan sebagai tumpuan pembangunan perekonomian (Prime Mover), terdapat permasalahan besar yang di alami oleh negara indonesia yaitu sampah. Sampah yang berasal dari aktivitas manusia menyebabkan pencemaran terhadap lingkungan sehingga sumber daya alam menjadi terhambat. Setiap tahunnya volume sampah akan terus meningkat selama aktivitas manusia berjalan. Kementrian Lingkungan Hidup mencatat rata-rata masyarakat indonesia menghasilkan 625 juta liter sampah setiap harinnya. Jumlah tersebut akan terus meningkat setiap tahunnya sesuai dengan kondisi lingkungannya. Daerah penghasil sampah terbanyak ialah pulau jawa dengan penduduk \pm 160 juta jiwa. Undang-undang Nomor 18 Tahun 2008 tentang pengelolaan sampah dan Peraturan Pemerintah Nomor 81 Tahun 2012 menyatakan perlunya perubahan paradigma terhadap pengelolaan sampah yaitu dari paradigma kumpul angkut - buang menjadi Reduce - Reuse - Recycle (Suryani, 2014)

Sampah merupakan hasil aktivitas manusia atau alam yang sudah tidak digunakan lagi karena telah diambil unsur atau fungsi utamanya, dari hasil aktivitas manusia maka banyak tidaknya sampah akan terus ada selama manusia masih beraktivitas, menurut World Health Organization (WHO) menyatakan sampah adalah sesuatu yang tidak digunakan, tidak dipakai, tidak disenangi atau sesuatu yang dibuang yan berasal dari kegiatan manusia (Chandra, 2006)

Dalam Undang- Undang No.18 Tahun 2008 mengenai pengelolaan sampah, jenis dan sumber yang telah diatur yaitu sampah rumah tangga yang berasal dari sisa kegiatan sehari hari di rumah tangga, sampah sejenis sampah rumah tangga yang berasal dari pasar, kantor, rumah makan, hotel, terminal dan sampah spesifik yang mengandung B3 atau bahan bahan berbahaya seperti pecahan kaca, batrai bekas dan bahan beracun lainnya. Teknik pengelolaan sampah pada pemukiman terdiri dari 5 aspek yaitu hukum dan peraturan, kelembagaan, teknis operasional, pembiayaan dan iuran, pemberdayaan masyarakat (Dobiki, 2018)

Salah satu cara untuk meningkatkan perekonomian di Desa Banangkah yaitu dengan melakukan pengelolahan bank sampah sehingga pemasukan desa akan bertambah dan melakukan pengelolahan bank sampah dapat menjaga kebersihan lingkungan di Desa Banangkah.

\section{TUJUAN}

1. Mengetahui pengelolahan bank sampah di Desa Banangkah

2. Meningkatkan perekonomian yang ada di Desa Banangkah dengan memanfaatkan sampah sebagai bahan dasar 


\section{LANDASAN TEORI}

\section{Bank Sampah}

Bank sampah merupakan suatu tempat pemilahan dan pengumpulan sampah yang dapat di daur ulang sehingga memiliki nilai ekonomi. Bank sampah dapat bermanfaat dalam mengurangi sampah yang ada di masyarakat. Sampah yang terkumpul akan di olah dengan sistem 3R. Pemilahan sampah dan pelaksanaan sistem 3R melibatkan secara langsung masyarakat sekitar. sistem 3R merupakan aktifitas yang dapat mengurangi sampah (Reduce), kegiatan penggunaan kembali sampah yang layak pakai (Reuse) dan mengolah sampah untuk dijadikan produk yang lain (Recycle) dengan menerapkan sistem 3R dapat mengurangi pencemaran lingkungan yang disebabkan oleh sampah ( Kristina, 2014)

Bank sampah adalah salah satu strategi penerapan 3R (Reuse, Reduce, Recycle ) dalam pengelolaan sampah masyarakat menjadi peran utama dalam pelaksanaannya. Bank sampah merupakan salah satu upaya dari penerapan Undang-Undang No.18 Tahun 2008 tentang pengelolaan sampah. Bank sampah merupakan kegiatan yang bersifat social engineering yang melatih masyarakat untuk memilah sampah dan menumbuhkan kesadaran terhadap pentingnya menjaga lingkungan. Bank sampah bermanfaat untuk mengurangi sampah yang ada baik sampah plastic maupun sampah non-plastik (Selomo et al, 2016 )

Permasalahn yang ada di masayrakat yaitu kurangnya kesadaran masyarakat akan sampah. Penggunaan Bank sampah ini bermanfaat mengurangi sampah yang ada di lingkungan masyarakat dan juga memngurangi dampak negative sampah yang ada di lingkungan. Bank sampah dapat dijadikan pekerjaan sehingga dapat meningkatakan ekonomi masyarakat bangkah di masa pandemi ini.

\section{Jenis - Jenis Sampah}

Menurut Kusuma dan Yuli (2017) Sampah terbagi menjadi tiga jenis dalam pengelolaan bank sampah yaitu :

1. Sampah Organik

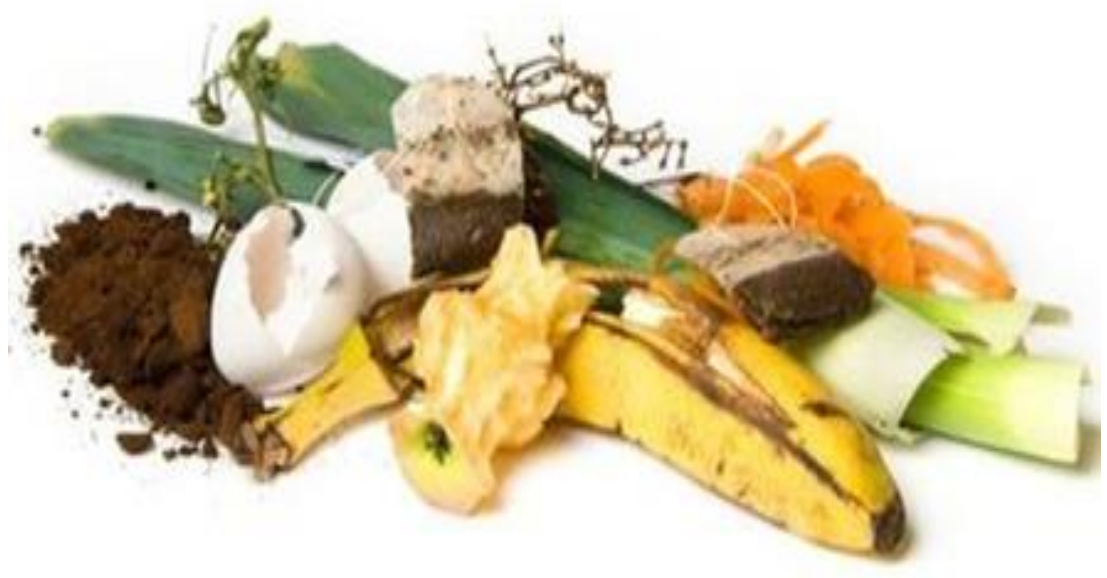

Gambar 2.1 Sampah Organik

Sampah organik merupakan sampah yang terdiri dari bahan - bahan yang dapat terurai secara alami atau biologis. Contoh dari sampah organik seperti sisa makanan dan guguran daun. 
2. Sampah Anorganik

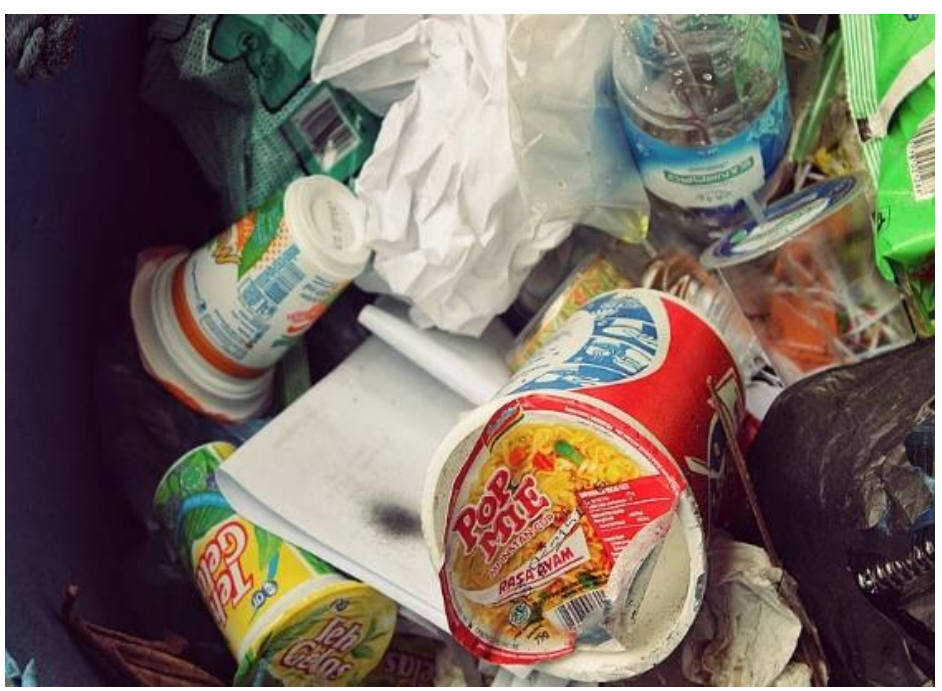

Gambar 2.2 Sampah Anorganik

Sampah anorganik merupakan sampah yang terdiri dari bahan - bahan yang tidak bisa terurai atau sulit terurai secara biologis ataupun alami. Penghancuran sampah anorganik membutuhkan penanganan lebih lanjut dan sampah anorganik dilakukan daur ulang atau pembaruan. Sampah jenis ini dapat disebut sampah kering.

3. Sampah B3

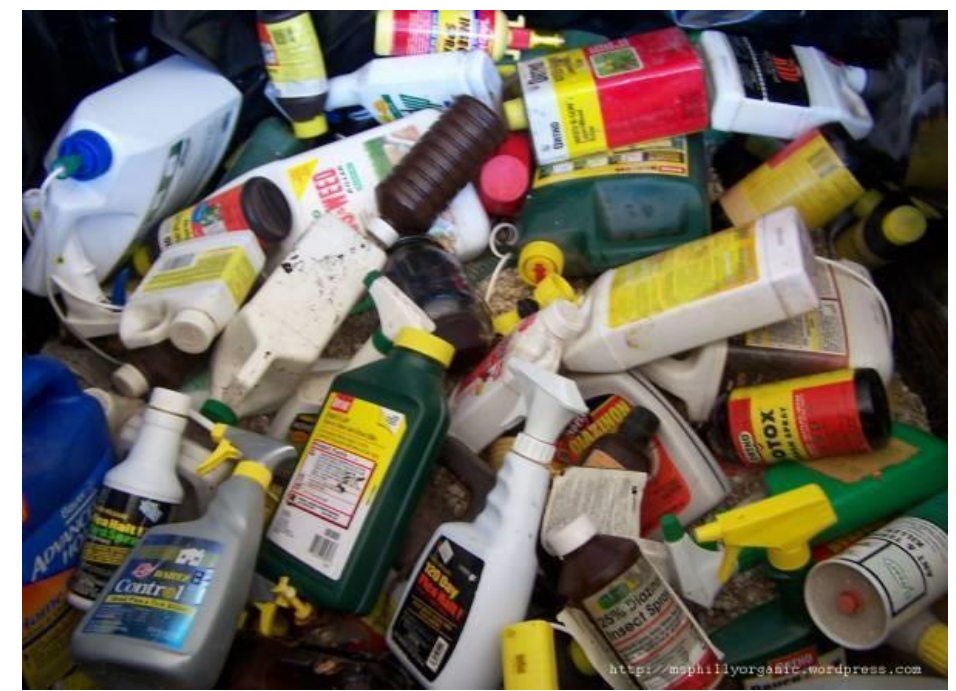

Gambar 2.3 Sampah B3

Sampah B3 merupakan sampah yang mengandung limbah dari bahan - bahan berbahaya dan beracun seperti limbah rumah sakit, limbah pabrik dan pecahan kaca. Sampah B3 nantinya akan di daur ulang untuk dijadikan sebuah produk.

\section{Manfaat Pengelolahan Bank Sampah}

Bank sampah memiliki peran yang cukup besar dalam menangani permasalahan sampah dimasyarakat. Bank sampah juga membuat sampah memiliki nilai ekonomi. Bank sampah merupakan gerakan ekonomi kreatif dan juga dapat menyelamatkan lingkungan dari pencemaran (Wardany et al, 2020)

Menurut Linda (2016) terdapat beberapa manfaat dari bank sampah yaitu:

1) Mengurangi pencemaran lingkungan

2) Mengurangi volume sampah

3) Mendidik masyarakat untuk bertanggung jawab terhadap sampah yang dihasilkan 
4) Meningkatkan rasa gotong royong dan kepedulian social

5) Menambah penghasilan anggota Desa Banangkah, Kecamatan Burneh Kabupaten bangkalan

6) Mengurangi Polusi Lingkungan

\section{METODOLOGI}

\section{Jenis Tulisan}

Metode yang digunakan di dalam artikel ilmiah ini merupakan metode penulisan kepustakaan yang digunakan secara deskriptif. Artikel ilmiah ini memaparkan terkait penggunaan bank sampah untuk mengurangi sampah yang ada dilingkungan masyarakat serta pemanfaatan sampah yang dapat menghasilkan peningkatan ekonomi di Desa Bangkah.

\section{Metode Pengumpulan Data}

Penulisan artikel ilmiah ini menggunakan pengumpulan data dari beberapa pustaka baik dari jurnal dan buku, selain itu pengumpulan data didapatkan dari tempat bank sampah di Desa banangkah, Kecamatan Burneh, kabupaten Bangkalan. Metode pengumpulan data ini berupa proses analisis dalam penyampaian pendapat dengan berfikir secara logis.

\section{HASIL DAN PEMBAHASAN}

Mekanisme Sistem Bank Sampah Yang Dapat Meningkatkan Perekonomian

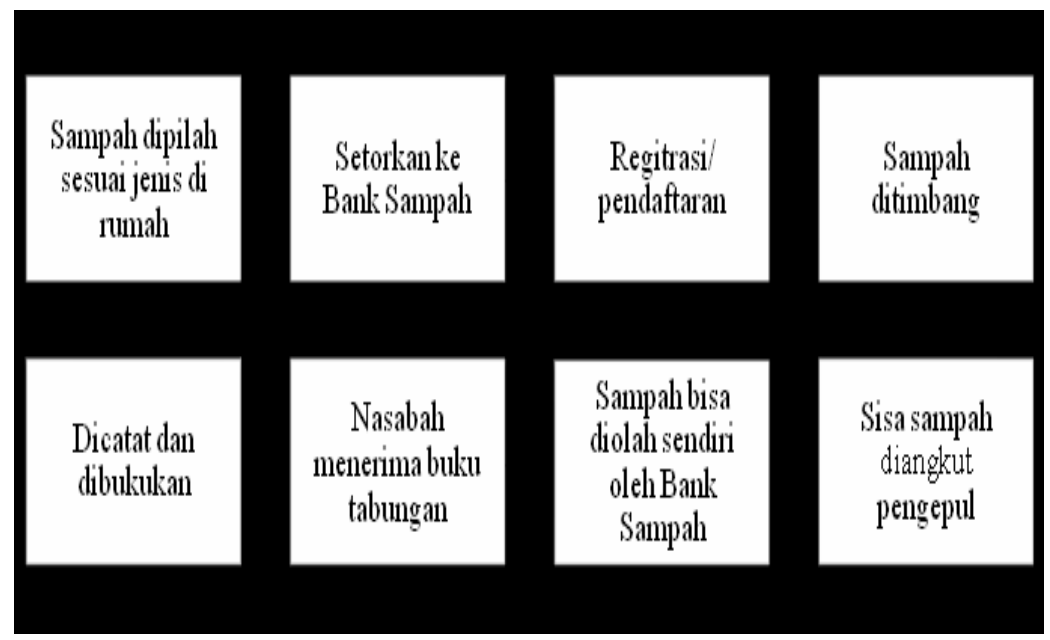

Gambar 3.1 Mekanisme Sistem Bank Sampah

Masyarakat terlebih dahulu memilah sampah sebelum disetorkan ke bank sampah. Pemilahan sampah dibagi ke dalam tiga kategori yaitu sampah organik, sampah anorganik dan sampah B3 dengan sistem bank sampah masyarakat secara tidak langsung telah mengurangi volume sampah per tahunnya. Langkah selanjutnya ialah penyetoran ke bank sampah. Penyetoran sampah ini memiliki waktu tertentu seperti seminggu tiga kali atau dua kali, hal tersebut dilakukan agar sampah tidak tertumpuk di lokasi bank sampah. Nasabah akan melakukan pendaftaran untuk pembuatan buku tabungan. Langkah selanjutnya ialah penimbangan. Sampah yang telah disetor kemudian ditimbang dan akan di catat kedalam buku nasabah, dalam penimbangan telah disepakati setiap kilo sampah memiliki harga yang berbeda beda. Selanjutnya sampah yang telah terkumpul di bank sampah akan di angkut oleh pengepul untuk proses daur ulang (Dewanti et al, 2020).

Bank sampah menjadi solusi dalam mengatasi sampah yang ada di masyarakat. Edukasi kesadaran dan keterampilan warga dalam pengolahan sampah dengan melakukan penerapan Reduce, Reuse, Recyle dan Replant 
merupakan hal penting dalam penyelasaian sampah yang ada di masyarakat atau dilingkungan desa Banangkah, kacamatan Burneh, Kabupaten Bangkalan. Kegiatan bank sampah merupakan konsep pengumpulan sampah yang nantinya akan menghasilkan uang. Pemberdayaan yang dilakukan kepada masyarakat terkait bank sampah dilakukan dengan proses penyuluhan, edukasi dan pelatihan (Heruman dan Asteria,2016).

Kegiatan bank sampah merupakan sistem pengelolaan sampah secara kolektif dengan memegang prinsip daur ulang tetapi tidak semua sampah dapat di daur ulang namun dapat dijadikan produk lainnya salah satu contohnya ialah sampah organik yang berasal dari aktivitas manusia. Sampah organik tidak dapat di daur ulang kembali namun dapat dijadikan sebagai pupuk kompos sehingga hasil dari pengelolaan pupuk kompos tersebut dapat menjadi suatu produk yang memiliki nilai ekonomi yang tinggi. Masyarakat yang mengikuti kegiatan bank sampah akan memiliki buku tabungan yang mana buku tabungan tersebut dapat diambil sesuai dengan kebutuhan. Dengan demikian pengelolaan bank sampah memberikan dampak positif terhadap perekonomian masyarakat dan juga terhadap lingkungan (Shentika, 2016)

\section{KESIMPULAN}

\section{Kesimpulan}

Berdasarkan dari rumusan masalah tersebut maka dapat disimpulkan :

1. Cara pengolahan bank sampah terbilang mudah. Masyarakat hanya perlu mengumpulkan sampah dan memilahnya dengan jenis yang sama selanjutnya masyarakat mengumpulkan sampah tersebut ke bank sampah untuk ditukarkan dengan uang.

2. Cara meningkatkan perekonomian di Desa Banangkah dengan cara melakukan pengolaan bank sampah. Sampah menjadi bahan dasar yang dapat dimanfaatkan sebagai pemasukan masyarakat desa selain itu dengan pengolaan bank sampah masyarakat juga dapat menjaga lingkungan sekitar dari pencemaran.

\section{DAFTAR PUSTAKA}

Baransano, H,K dan Jubhar C,M. 2011. Eksploitasi Dan Konservasi Sumberdaya Hayati Laut Dan Pesisir Di Indonesia. Jurnal Biologi Papua. III(1): 39 - 45.

Chandra, Budiman. 2006. Pengantar Kesehatan Lingkungan. EGC. Jakarta SubektiI

Dobiki, J. 2018. Analisis Ketersedian Prasarana Persampahan Di Pulau Kumo Dan Pulau Kakara Di Kabupaten Halmahera Utara. Jurnal Spasial. V(2): 220-228

Dewanti, M., Eko, P.P \& Lubna, S. 2020. Analisa Efektifitas Bank Sampah Sebagai Alternatif Pengelolaan Sampah Dalam Mencapai Smart City Di Kabupaten Kulon Progo. Jurnal Ilmu Administrasi Publik. V(1): 21-29.

Ghufron, M. H. dan Kordi, K, 2012. Ekosistem Mangrove Potensi, Fungsi, Dan Pengelolaan. Jakarta: PT. Rineka Cipta.

Heruman, H dan Asteria D. 2016. Bank sampah Sebagai Alternatif Strategi Pengolahan Sampah Berbasis masyarakat di Tasikmalaya (Waste Banks as an Alternative of Community-Based Waste Management Strategy in Tasikmalaya). Jurnal Manusia dan Lingkungan. XXIII(1):1-10.

Kristina, J.H.2014. Model Konseptual Untuk Mengukur Adaptabilitas Bank Sampah Di Indonesia. Jurnal TI UNDIP. IX(1): 19-28

Kusuma, P.D \& Yuli A.2017.Sistem Pengolahan Data Bank Sampah (Study Kasus : Bank Sampah Bankit Pondok I Ngemplak Sleman). Jurnal Manajemen Dan Informatika Pelita Nusantara. XXI(1): 32-41

Linda,R.2016.Pemberdayaan Ekonomi Kreatif Melalui Daur Ulang Sampah Plastik (Studi Kasus Bank Sampah Berlian Kelurahan Tangkerang Labuai). Jurnal Al-Iqtishad. XII(1): 1-19 
Shentika, A.,P.2016.Pengelolaan Bank Sampah Di Kota Probolinggo. Jurnal Ekonomi \& Studi Pembangunan. VIII(1): 92100

Suryani, S.A.2014.Peran Bank Sampah Dalam Efektivitas Pengelolaan Sampah (Studi Kasus Bank Sampah). Jurnal Masalah Masalah Sosial . V(1): 71-84

Selomo, M., Agus, B.B.,Anwar, M dan Muammar.2016. Bank Sampah Sebagai Salah Satu Solusi Penanganan Sampah Di Kota Makasar. Jurnal MKMI. XII(4): 232-240

Wardany, K., Reni, P.S \& Erni M.2020.Sosialisasi Pendirian “Bank Sampah” Bagi Peningkatan Pendapatan Dan Pemberdayaan Perempuan Di Margasari. Jurnal Pengabdian Kepada Masyarakat. IV(2): 364-372. 